\title{
Potential role of HMG CoA reductase inhibitor on oxidative stress induced by advanced glycation endproducts in vascular smooth muscle cells of diabetic vasculopathy
}

\author{
Se-Jung Yoon ${ }^{1 *}$, Young Won Yoon ${ }^{2 *}$, \\ Byoung Kwon Lee ${ }^{2,6}$, Hyuck Moon Kwon ${ }^{2,6}$, \\ Ki-Chul Hwang ${ }^{3}$, Myunghyun Kim ${ }^{2}$, \\ Woochul Chang ${ }^{3}$, Bum-Kee Hong ${ }^{2}$, \\ Young-Ho Lee ${ }^{4}$, Soon-Jung Park ${ }^{5}$, \\ Pil-Ki Min ${ }^{2}$ and Se-Joong Rim ${ }^{2}$ \\ ${ }^{1}$ Cardiology Division \\ National Health Insurance Corporation \\ Ilsan Hospital \\ Goyang 410-719, Korea \\ ${ }^{2}$ Cardiology Division \\ Department of Internal Medicine \\ Gangnam Severance Hospital \\ Yonsei University College of Medicine \\ Seoul 135-720, Korea \\ ${ }^{3}$ Cardiovascular Research Institute \\ Yonsei Cardiovascular Hospital \\ ${ }^{4}$ Physiology Department \\ ${ }^{5}$ Environmental Medical Biology Department \\ Yonsei University College of Medicine \\ Seoul 120-752, Korea \\ ${ }^{6}$ Corresponding authors: Tel, 82-2-2019-3310; Fax, 82-2-2019-4817; \\ E-mail, kwonhm@yuhs.ac (H.M. Kwon), cardiobk@yuhs.ac (B.K. Lee) \\ *These authors contributed equally to this work. \\ DOI 10.3858/emm.2009.41.11.086
}

Accepted 29 June 2009

Abbreviations: AGEs, advanced glycation endproducts; DM, diabetes mellitus; HMG CoA, 3-hydroxy-3-methylglutaryl-coenzyme A; MI, myocardial infarction; RAGE, receptor for AGE; RASMC, rat aortic smooth muscle cell; ROS, reactive oxygen species; VSMC, vascular smooth muscle cell

\begin{abstract}
Advanced glycation endproducts (AGEs)-induced vascular smooth muscle cell (VSMCs) proliferation and formation of reactive oxygen species (ROS) are emerging as one of the important mechanisms of diabetic vasculopathy but little is known about the antioxidative action of HMG COA reductase inhibitor (statin) on AGEs. We hypothesized that statin might reduce AGEs-induced intracellular ROS of VSMCs and analyzed the possible mechanism of action of statin in
\end{abstract}

AGEs-induced cellular signaling. Aortic smooth muscle cell of Sprague-Dawley rat (RASMC) culture was done using the different levels of AGEs stimulation in the presence or absence of statin. The proliferation of RASMC, ROS formation and cellular signaling was evaluated and neointimal formation after balloon injury in diabetic rats was analyzed. Increasing concentration of AGEs stimulation was associated with increased RASMC proliferation and increased ROS formation and they were decreased with statin in a dose-dependent manner. Increased NF- $K B$ p65, phosphorylated ERK, phosphorylated P38 MAPK, cyclooxygenase-2, and c-jun by AGEs stimulation were noted and their expression was inhibited by statin. Neointimal formation after balloon injury was much thicker in diabetic rats than the sham-treated group but less neointimal growth was observed in those treated with statin after balloon injury. Increased ROS formation, subsequent activation of MAPK system and increased VSMC proliferation may be possible mechanisms of diabetic vasculopathy induced by AGEs and statin may play a key role in the treatment of AGEs-induced diabetic atherosclerosis.

Keywords: cyclooxygenase 2; diabetes mellitus; extracellular signal-regulated MAP kinases; hydroxymethylglutaryl-CoA reductase inhibitors; muscle, smooth, vascular; NFKB; p38 mitogen-activated protein kinases; proto-oncogene proteins c-jun; reactive oxygen species

\section{Introduction}

Recent studies have demonstrated that advanced glycation endproducts (AGEs) and their receptorligand interactions play a key role in neointimal formation after vascular injury, irrespective of diabetes status (Brownlee et al., 1988; Sakaguchi et al., 2003; Stephenson et al., 2003; Zhou et al., 2003). AGEs stimulate the activation of the NFKBdependent pathways and MAPK and subsequently induce proinflammatory mediators and increase oxidative stress (Bierhaus et al., 1997).

Reactive oxygen species (ROS) can function as signal transduction molecules and play an important role in the inflammatory process and atheroscle- 
A

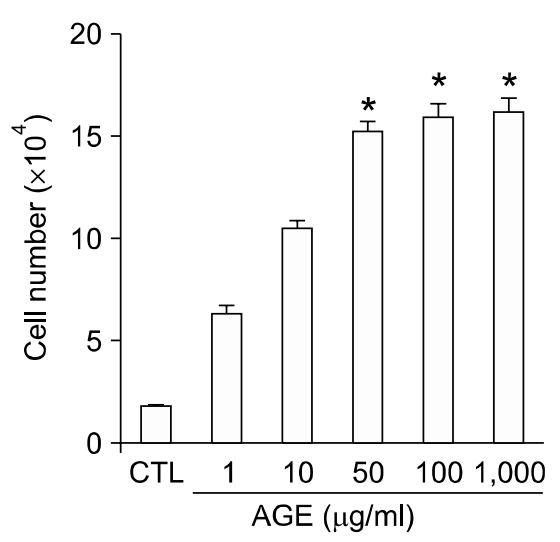

B

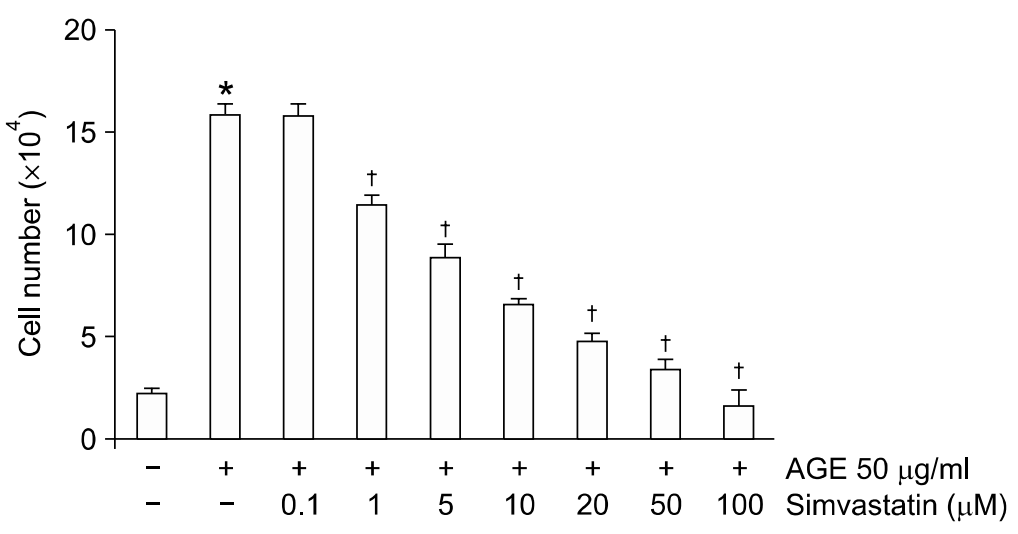

Figure 1. Effect of AGEs and statin on proliferation of RASMCs. Proliferation was increased with AGEs treatment dose-dependently (A) and decreased with statin dose-dependently (AGE $50 \mu \mathrm{g} / \mathrm{ml}$ ) (B). Cell proliferation was determined by MTT assay. Data are expressed as mean \pm SEM $(n=5)$. ${ }^{*} P<$ 0.05 versus control; ${ }^{\dagger} P<0.05$ versus AGEs. CTL, control; AGEs, advanced glycation endproducts.

rosis (Brown et al., 1999; Davignon, 2004). The antioxidative effect of statin has recently been noted as one of its pleiotrophic effects. Statin reduces intracellular ROS in endothelial cells by S-nitrosylation of thioredoxin (Haendeler et al., 2004) as well as other various effects (Kim et al., 2009). Recently, several reports have suggested that statin could act as an antioxidant in experimental atherosclerosis in animals (Singh et al., 1997; Takemoto et al., 2001; Wassmann et al., 2002), inhibiting oxidation of LDL by activated monocyte-derived macrophages (Giroux et al., 1993). Another recent article revealed that statin inhibited p38 MAPK and consequently inhibited membrane translocation of the small $G$ protein

A

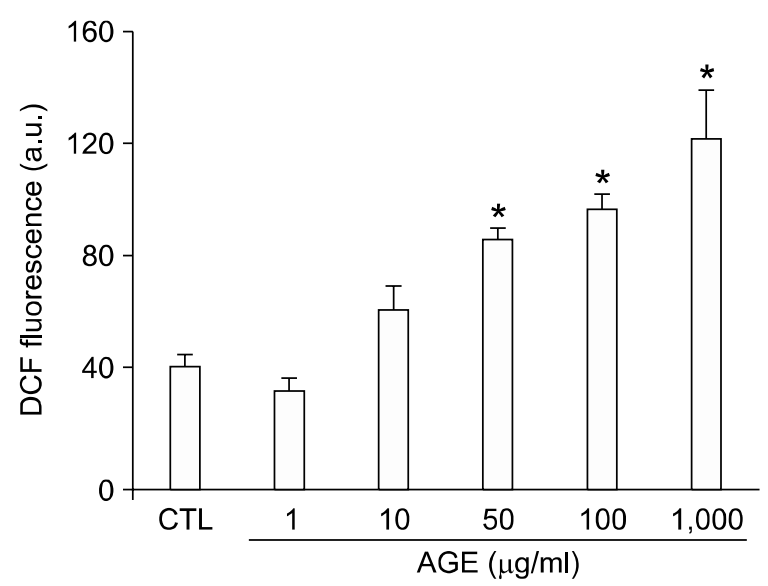

family members (Ras1- and RhoA-) (Senokuchi et al., 2005). However despite the potent impact of statin on atherosclerosis, little is known about the molecular mechanism of statin as antioxidants.

Therefore, we hypothesized that statin might reduce AGEs-induced intracellular ROS generation and also analyzed the possible mechanism of action of statin in ROS-induced cellular signaling.

\section{Results}

\section{Effect of AGEs and statin on VSMC proliferation}

In order to investigate whether statin affects RASMC

Figure 2. Effect of AGEs and statin on formation of intracellular ROS in RASMCs. Results shown are increased oxidative stress with AGEs treatment dose-dependently (A) and suppressive effect of statin on oxidative stress (AGE $50 \mu \mathrm{g} / \mathrm{ml})$ (B). Data are expressed as mean \pm SEM $(n=5)$. ${ }^{*} P<0.05$ versus control; ${ }^{\top} P<0.05$ versus AGEs. CTL, control; AGEs, advanced glycation endproducts. 


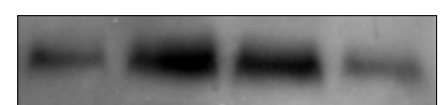

$\mathrm{NF}-\kappa \mathrm{B}$ activation

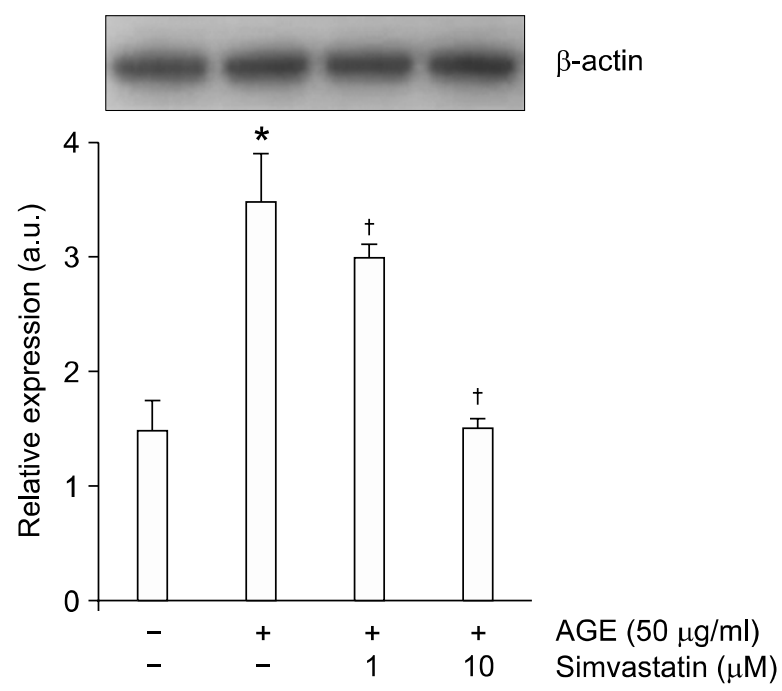

Figure 3. Effect of statin on activation of NFKB p65 in RASMCs treated with AGEs. Western blot for $\beta$-actin is shown as a protein loading control. Compared to cells treated with AGEs alone, cells treated with statin demonstrated significant inhibition of NFKB p65 expression. Symbols - and + indicate the absence and presence of AGEs or simvastatin, respectively. Data show a representative gel of NFKB p65 products and a bar graph of data quantitated as relative expression (a.u.) over respective control (mean \pm SEM) $(n=5)$. ${ }^{*} P<0.05$ versus control, ${ }^{\dagger} P<0.05$ versus AGEs-treated. AGEs, advanced glycation endproducts.

A

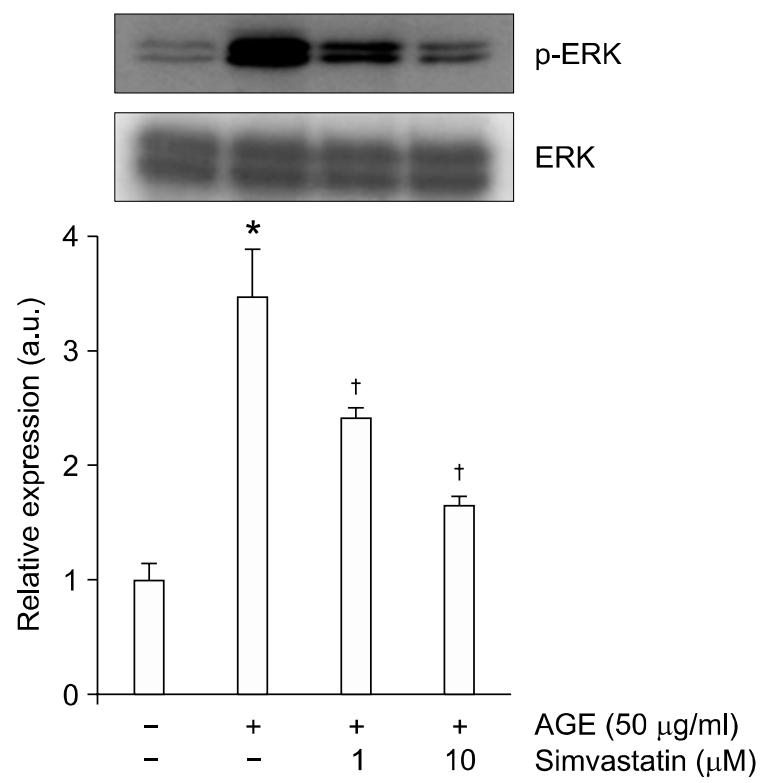

proliferation upon AGEs treatment, RASMCs were treated with AGEs in the presence or absence of statin and cell proliferation assay was performed. As shown in Figure 1A, AGEs-induced increase in cell proliferation and augmentation of cell proliferation induced by $50 \mu \mathrm{g} / \mathrm{ml}$ of AGEs were concentration-dependent $(7.2 \pm 2.4$-fold increase compared to controls at $50 \mu \mathrm{g} / \mathrm{ml}$ of AGEs). The maximal response was obtained at $50 \mu \mathrm{g} / \mathrm{ml}$ of AGEs. Statin inhibited augmentation of cell proliferation induced by AGEs in a dose-dependent manner (Figure 1B).

\section{Effect of AGEs and statin on formation of intracellular ROS in RASMCs}

As shown in Figure 2A, the degree of oxidative stress is increased with AGEs treatment dose-dependently and the increase was significant at 50 $\mu \mathrm{g} / \mathrm{ml}$ of AGEs (1.5 \pm 1.0 -fold increase compared to controls at $50 \mu \mathrm{g} / \mathrm{ml}$ of AGEs). Statin inhibited augmentation of oxidative stress induced by 50 $\mu \mathrm{g} / \mathrm{ml}$ of AGEs (Figure $2 B$ ).

\section{Effect of statin on activation of NFKB p65 in RASMCs}

To confirm the inhibitory effect of statin on expression of $\mathrm{NF} \kappa \mathrm{B}$, changes in $\mathrm{NF} \kappa \mathrm{B}$ p65 levels were estimated by immunoblot analysis. AGEs $(50 \mu \mathrm{g} / \mathrm{ml})$

B

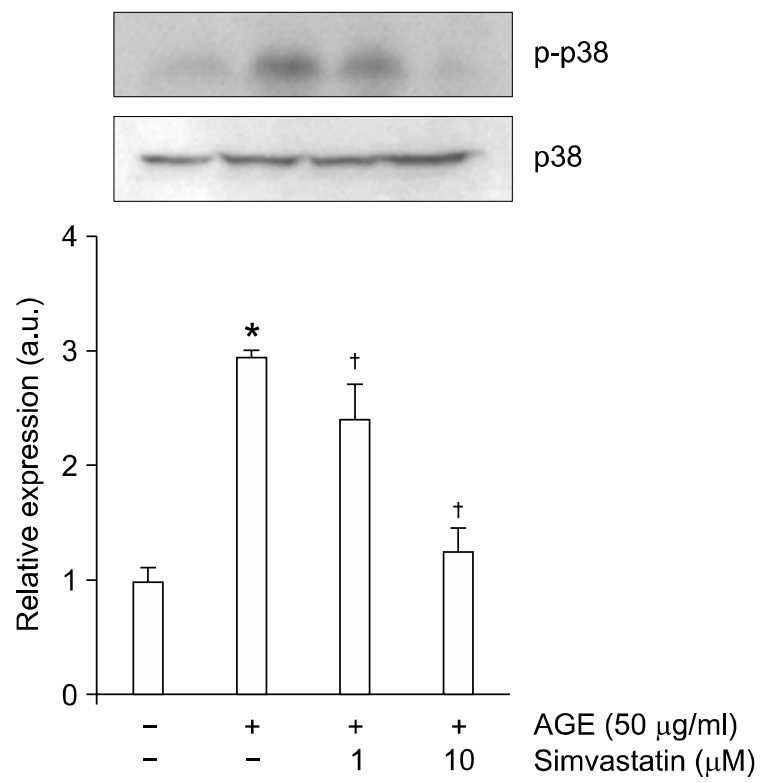

Figure 4. Effect of AGEs and statin on phosphorylation of MAPK in RASMCs treated with AGEs. Western blot for ERK and p38 in AGEs- or statin-treated RASMCs. The AGEs-treated one revealed increased activation of ERK (A) and p38 (B) and decreased activation with $1 \mu M$ of statin. Symbols - and + indicate the absence and presence of AGEs or simvastatin, respectively. Data show a representative gel of ERK and p38 products and a bar graph of data quantitated as relative expression (a.u.) over respective control (mean \pm SEM) $(n=5)$. ${ }^{*} P<0.05$ versus control, ${ }^{+} P<0.05$ versus AGEs-treated. AGEs, advanced glycation endproducts. 
induced several-fold increase in NFкB p65 (2.1 \pm 1.3-fold increase compared to controls) expression but statin significantly inhibited AGEs-induced augmentation of $\mathrm{NF} \kappa \mathrm{B}$ expression (Figure 3 ).

\section{Effect of AGEs and statin on phosphorylation of MAPK in RASMCs}

To confirm the inhibitory effect of statin on expression of MAPK, changes in MAPK levels were estimated by immunoblot analysis. AGEs $(50 \mu \mathrm{g} / \mathrm{ml})$ induced several-fold increase in ERK and p38 (3.1 \pm 1.2 -fold and $2.9 \pm 1.0$-fold increase compared to controls) expression but statin significantly inhibited AGEs-induced augmentation of ERK and p38 expression (Figure 4). This suggests that statin significantly inhibits activation of MAPK increased with AGEs.

\section{Effect of statin and siRNA on activation of MAPK in RASMCs}

To determine whether AGEs are coupled to ERK activation via RAGE, siRNA for RAGE was pretreated. Fifty $\mu \mathrm{g} / \mathrm{ml}$ of AGEs increased phosphory-

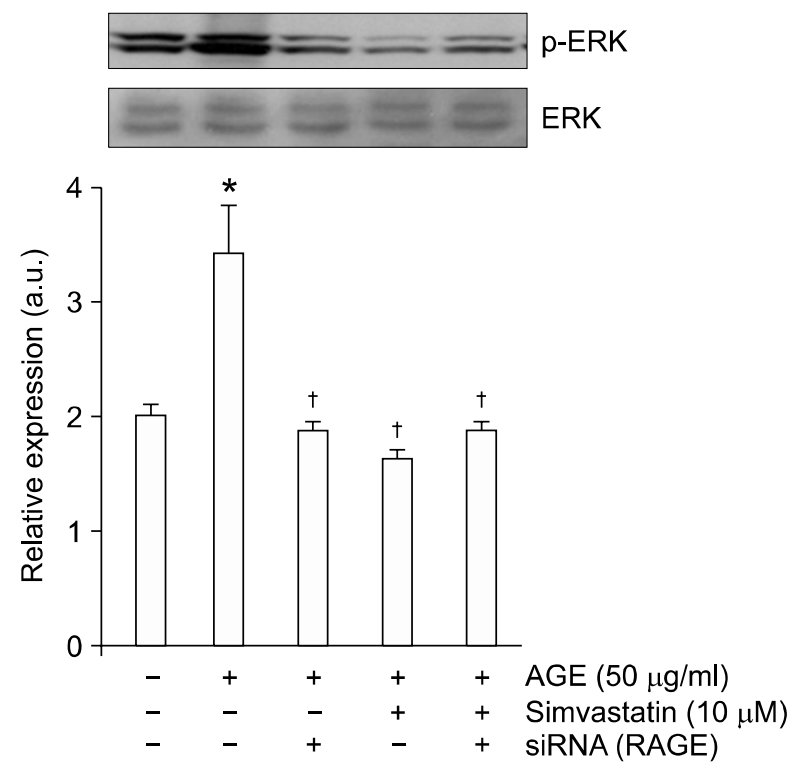

Figure 5. Effect of siRNA molecules targeted at RAGE on phosphorylation of MAPK in RASMCs treated with AGEs. Western blot for ERK in AGEs-, siRNA-, or statin-treated RASMCs. For function-blocking experiments, siRNA molecules targeted at RAGE mRNA was used. There was no difference in ERK activation between both and individual treatment with statin and siRNA for RAGE. Symbols - and + indicate the absence and presence of AGEs, simvastatin, or siRNA, respectively. Data show a representative gel of ERK products and a bar graph of data quantitated as relative expression (a.u.) over respective control (mean \pm SEM) ( $n=$ 5). ${ }^{*} P<0.05$ versus control, ${ }^{\dagger} P<0.05$ versus AGEs-treated. AGEs, advanced glycation endproducts; siRNA, small interfering RNA. lation of ERK $1.7 \pm 0.8$-fold compared to controls and $10 \mu \mathrm{M}$ of statin decreased phosphorylation of ERK. Additionally, AGEs-induced ERK activation was decreased to basal control level by RAGE inhibition. Furthermore, there was no difference in ERK activation between both and individual treatment with statin and siRNA for RAGE. These results indicate that RAGE mediated ERK activation by AGEs and statin blocked the process induced by RAGE-AGE interaction (Figure 5).

\section{Effect of statin on suppression of c-jun and COX-2 mRNA expression in RASMCs}

The inhibition of expression of c-jun and COX-2 at the mRNA level was demonstrated by RT-PCR. The treatment of RASMCs with AGEs resulted in increased expression levels of c-jun and COX-2, which were reduced by pretreatment with statin (Figure 6). The results indicated that statin has an inhibitory effect on expression levels of $c$-jun and COX-2.

\section{Impact of statin on neointimal hyperplasia and expression of COX-2 in carotid artery of diabetic rat}

Compared to controls, neointimal formation in the carotid artery of diabetic model showed increased proliferation. However, diabetic model treated with statin showed more reduced neointimal formation than those not treated (Figure 7A-C and bar graph). COX-2 staining was more abundant in lesions of the carotid artery from AGEs-treated rats but markedly decreased after diabetic model was treated with statin (Figure 7D-F).

\section{Discussion}

In the present study, we provide evidence of the critical involvement of statin in the process of AGEs-induced intracellular ROS formation of VSMCs. Furthermore, the present findings are the first, to our knowledge, to demonstrate a mechanism of inhibitory effect of statin on the process of developing diabetic vasculopathy in view of AGEs-induced intracellular oxidative stress and consequent cellular signaling.

Type 2 diabetes mellitus (DM) patients without a prior myocardial infarction (MI) have a similar risk for coronary artery-related events as non-diabetic individuals who have had a prior MI. Recent work has focused on the role of AGEs and RAGE in macro- and microvascular complications in DM, and there are several potential mechanisms by which AGEs may be involved in macrovascular 
A

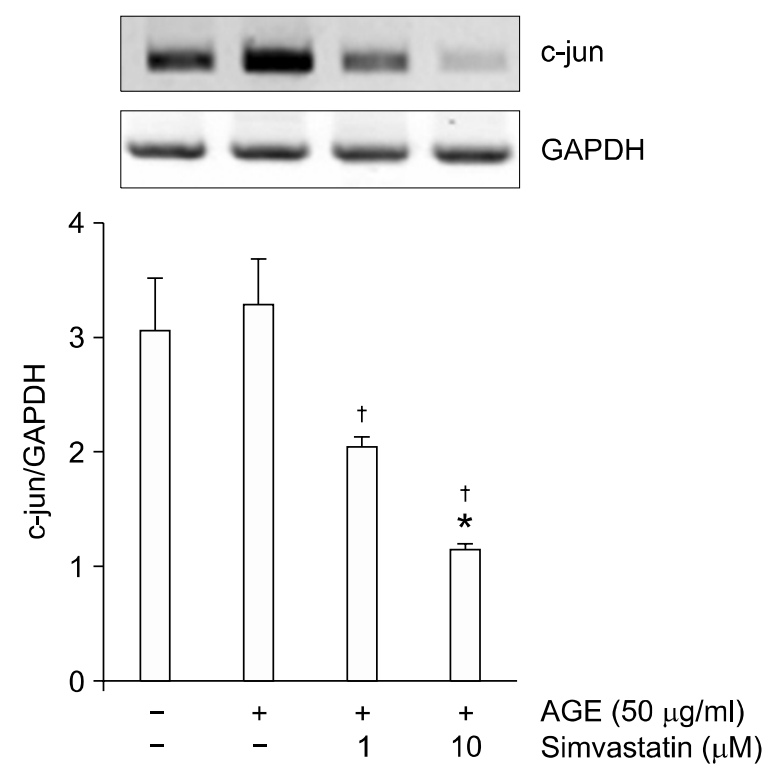

B

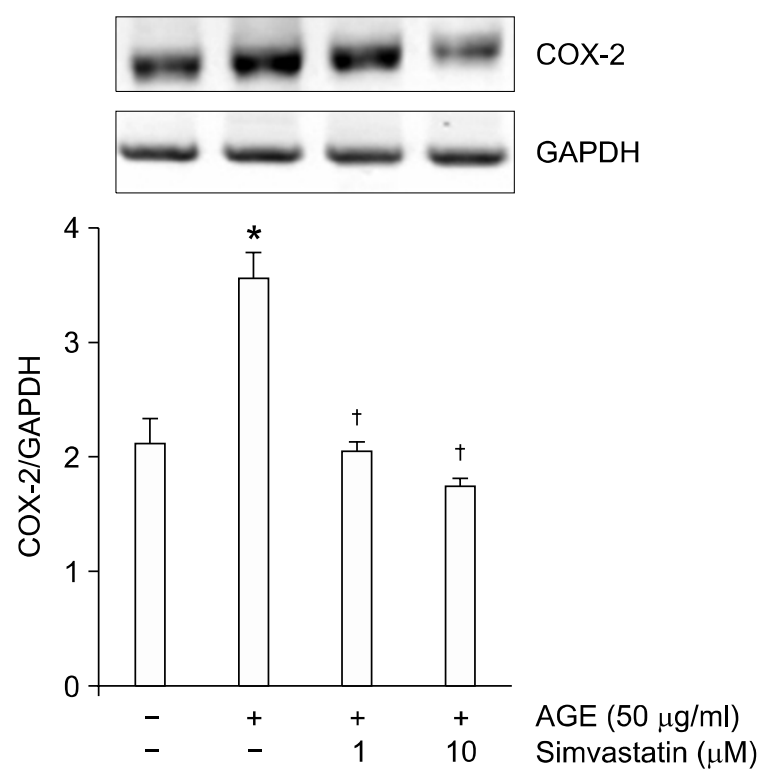

Figure 6. Effect of statin on suppression of protooncogene, c-jun, and COX-2 mRNA expression induced by AGEs. Expression levels of analysis by RT-PCR. Expression of c-jun (A) and COX-2 (B) revealed increase with AGEs and decrease with statin dose-dependently. Symbols - and + indicate the absence and presence of AGEs or simvastatin, respectively. Data show a representative gel of c-jun and COX-2 products and a bar graph of data quantitated as ratio of protein to its respective GAPDH signal intensity (mean \pm SEM) $(n=5)$. ${ }^{*} P<0.05$ versus control; ${ }^{\dagger} P<0.05$ versus AGEs-treated. AGEs, advanced glycation endproducts.

disease (Kanauchi et al., 2001; Rojas and Morales, 2004). Binding of AGEs to their receptor RAGE on cell surfaces including endothelial cells and VSMCs induces an intracellular oxidative stress response characterized by increased activation of transcription factors such as NFKB (Baynes and Thorpe, 1999). Oxidative stress of the vascular wall is a hallmark of atherosclerosis (Haendeler et al., 2004), and consequent activation of the NFKB and MAPK systems may be a possible mechanism of AGEs-induced vasculopathy (Cuccurullo et al., 2006). More recently, the role of ROS as a signal molecule has gained increasing attention. The cytotoxicity of ROS may be associated with the effect on signal pathways such as NFKB to induce pathology. There are also studies demonstrating that treatment of monocytes with in vitro prepared AGEs or the specific RAGE ligand can significantly increase COX-2 mRNA and its proinflammatory products in THP-1 human monocytes (Shanmugam et al., 2003). COX-2 and its proinflammatory products have been implicated in the pathogenesis of atherosclerosis, and it is also induced by oxidized lipids (Schonbeck et al., 1999; Hong et al., 2000; Burleigh et al., 2002; Pontsler et al., 2002). There are many studies demonstrating that interaction of RAGE and its ligand is closely correlated with cell migration, invasion, proliferation, survival and motility (Cipllone et al., 2003; Arumugam et al., 2004; 2005) induced by intracellular signaling pathways, including GTPases, Cdc42, Rac, MAPK, ERK 1/2, p38, JNK and NFKB (Rauvala et al., 2000; Taguchi et al., 2000).

Recent experimental studies suggested that the beneficial effects of statin in patients at risk for cardiovascular disease are not only a result of an improved lipid profile but also mediated by direct vasculoprotective actions (anti-inflammatory and endothelial cell protective actions) (Oda and Keane, 1999; Takemoto and Liao, 2001; Haendeler et al., 2004; Senokuchi et al., 2005). Moreover, in a recent study, RAGE suppression by simvastatin is emphasized to be largely dependent on the reduction of AGEs generation by myeloperoxidase. The antioxidant effects of statin are especially important in aspects of diabetic complications such as macro- or microvascular pathology but little is known about the pleiotrophic action of statin on AGEs.

ROS itself is known to be induced by the activation of NADPH oxidase from the reaction between AGE and RAGE, therefore, we investigated whether statin blocks VSMC proliferation through inhibition of ROS-induced proliferation and the inflammation pathway. This hypothesis was derived from the point that AGE-RAGE interaction may be 

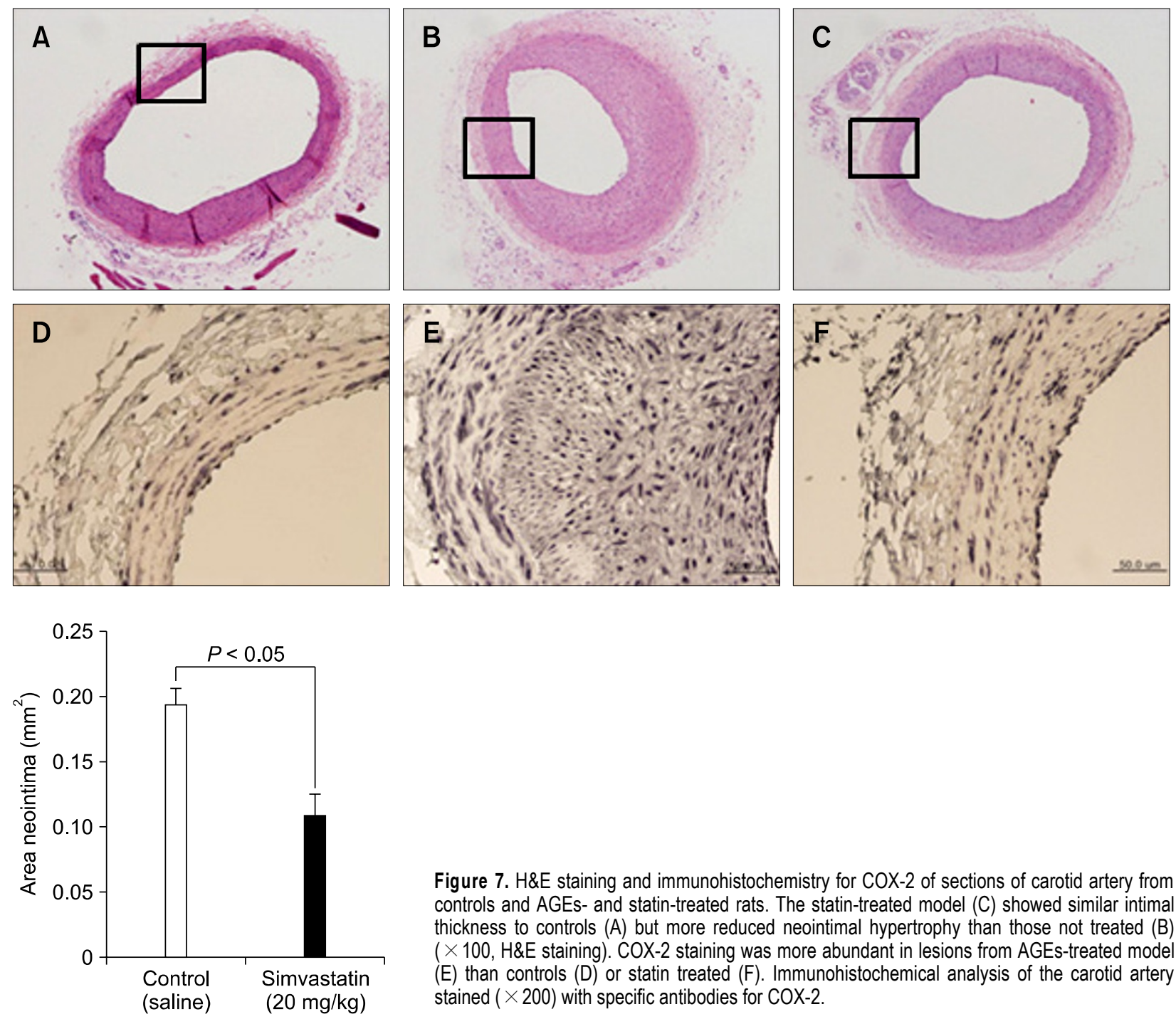

Figure 7. H\&E staining and immunohistochemistry for COX-2 of sections of carotid artery from controls and AGEs- and statin-treated rats. The statin-treated model (C) showed similar intimal thickness to controls $(A)$ but more reduced neointimal hypertrophy than those not treated $(B)$ ( $\times 100, H \& E$ staining). COX-2 staining was more abundant in lesions from AGEs-treated model $(E)$ than controls (D) or statin treated (F). Immunohistochemical analysis of the carotid artery stained $(\times 200)$ with specific antibodies for COX-2.

the upstream mechanism that increases formation of ROS and resultant VSMC proliferation. Therefore, we designed a schema showing the possible cascade of mechanism of diabetic vasculopathy induced with AGEs and the inhibitory action of statin in this process (Figure 8).

Our data showed increased cell proliferation and inflammatory reactions with AGEs treatment in dose-dependent manner and reduced cell proliferation, inflammatory cellular signaling and protein expression of RASMC with statin. To clarify the inflammatory and proliferative actions, we used proteins of NFKB p65, p38, ERK, COX-2, and c-jun as important factors in inflammatory cascade. Cuccurullo et al. (2006) characterized the effect of simvastatin on the expression of RAGE and RAGE-dependent plaque-destabilizing genes such as COX-2 in human atherosclerotic plaques. They hypothesized that simvastatin might inhibit plaque RAGE expression by decreasing MPO-dependent AGE generation and in turn, contribute to plaque stabilization by inhibiting biosynthesis of PGE2-dependent metalloproteinase, responsible for plaque rupture (Cipllone et al., 2003). Our data did not show the difference of $A G E$ or RAGE expression between controls and those treated with statin. This may be a limitation of our study, but our hypothesis that statin may block the process from RAGE-AGE interaction to ROS generation was supported by siRNA data.

To determine whether statin suppresses cellular signaling induced by RAGE-AGE interaction, we examined the effect of siRNA molecules targeted at RAGE mRNA for function-blocking experiments. ERK activation was increased compared to controls with AGEs and decreased activation was 


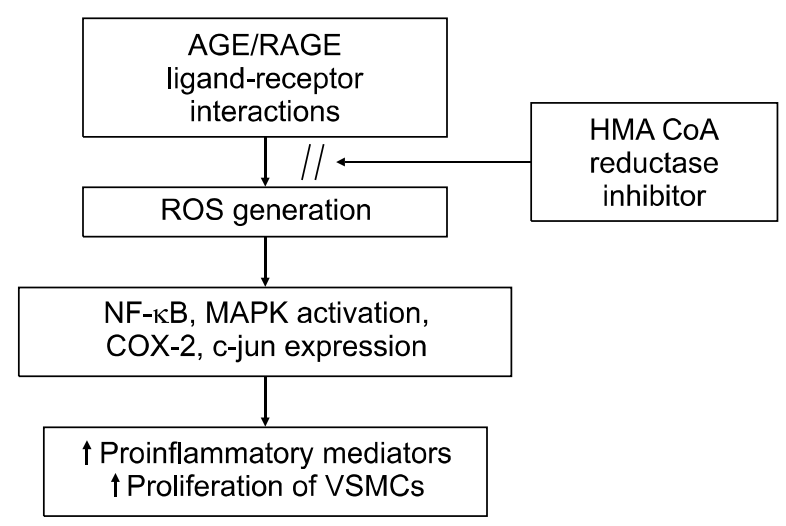

Figure 8. Schema of possible mechanism of inhibitory effect of statin on AGEs-induced vasculopathy. In the cascade of AGEs-induced ROS formation and inflammatory and proliferative cellular signaling, statin may act as a blocker of the process from AGE-RAGE interaction to ROS generation.

examined with statin. In addition, AGEs-induced ERK activation was decreased to basal control level by RAGE inhibition. Furthermore, there was no difference in ERK activation between both individual treatment with statin and SiRNA for RAGE. This indicates that RAGE mediated ERK activation by AGEs and statin blocked the process induced by RAGE-AGE interaction.

Recent experimental studies emphasize the antioxidative effects of statin and suggest that statin reduces ROS in endothelial cells by S-nitrosylation of thioredoxin (Takemoto and Liao, 2001; Haendeler et al., 2004). Recently, several reports have suggested that statin could act as an antioxidant in experimental atherosclerosis in rabbits (Giroux et al., 1993; Singh et al., 1997; Takemoto et al., 200; Wassmann et al., 2002), inhibiting oxidation of LDL by activated monocyte-derived macrophages. The ROS formation in our data increased with AGEs stimulation and reduced with statin treatment in dose-dependent manner as in other studies.

And in vivo study, many other articles revealed the anti-atherogenic effects of statin by using vascular injury model (Komukai et al., 1999; Chen et al., 2002) and have suggested that the inflammatory and proliferative responses are enhanced in diabetes and may explain the observed increased restenosis rate (Kornowski et al., 1997; Park et al., 2001), that was the same with this study.

In the present study, statin reduced AGE-RAGE interaction-induced increased intracellular oxidative stress (ROS) and ROS-induced cellular signaling in VSMCs. Consequently, it brought the suppression of neointimal hypertrophy and expression of COX-2 in the carotid artery of diabetic rat model. However, it remains possible that statin also has many additional effects on diabetic vasculopathy and further studies will be necessary to fully understand the action of statin.

We used a high dose of $20 \mathrm{mg} / \mathrm{kg}$ in rats but the dose in humans is lower, so the limitation can be that we did not suggest the clinical dose in humans. Because the effect of various chemical structures of statins on ROS formation can be different and we used only one type of statin, it may be another limitation of this study.

The antioxidant effects of statin are especially important in aspects of diabetic complications such as macro- or microvascular pathology. This study demonstrated the possible mechanism of action of statin on the antiproliferative effects of VSMCs of diabetic model. Conclusively, statin is expected to play a key role in the treatment of AGEs-induced diabetic vasculopathy.

\section{Methods}

\section{Experimental materials and animals}

The HMG CoA reductase inhibitor simvastatin was a generous gift from MRL (Merck \& Co., Inc., Rahway, NJ).

Six- to eight-week-old male Sprague-Dawley rats $(200 \mathrm{~g}$ initial weight) were given standard chow and water. They were injected with streptozocin (STZ, $80 \mathrm{mg} / \mathrm{kg}$ ) via intraperitoneal route and hyperglycemia was confirmed by blood glucose meter (Accu-Chek Advantage, Boehringer Mannheim, Mannheim, Germany) within 1 wk post-STZ. Diabetic models were confirmed by blood glucose levels over $250 \mathrm{mg} / \mathrm{dl}$. Rats treated with STZ that did not demonstrate significant elevation of blood glucose $(<250$ $\mathrm{mg} / \mathrm{dl}$ ) were excluded from the study. Animals were handled in compliance with the Guiding Principles in the Care and Use of Animals. Twenty $\mathrm{mg} / \mathrm{kg}$ of statin was mixed with pulverized standard chow and 5 rats were treated for $8 \mathrm{wks}$ from the 16th wk. After $8 \mathrm{wks}$, carotid artery balloon injury was performed and after 4 wk of more treatment, rats were sacrificed for analysis. The investigation conforms with the Guide for the Care and Use of Laboratory Animals published by the US National Institutes of Health (NIH Publication No. 85-23, revised 1996).

\section{Isolation of rat aortic smooth muscle cells (RASMC) and cell culture}

Rat aortic smooth muscle cells (RASMCs) were isolated as previously described (Takemoto and Liao, 2001). The thoracic aortas from 6- to 8-wk-old rats were removed and transferred in serum-free DMEM (Invitrogen Co., Carlsbad, CA) containing 100 units $/ \mathrm{ml}$ of penicillin and $100 \mu \mathrm{g} / \mathrm{ml}$ of streptomycin. The aortas were freed from connective tissue, transferred to a Petri dish containing $5 \mathrm{ml}$ of an enzyme dissociation mixture containing DMEM with 1 $\mathrm{mg} / \mathrm{ml}$ of collagenase type I (Sigma, St. Louis, MO) and 0.5 $\mu \mathrm{g} / \mathrm{ml}$ of elastase (USB Bioscience, Cleveland, $\mathrm{OH}$ ), and incubated for $30 \mathrm{~min}$ at $37^{\circ} \mathrm{C}$. The aorta was then transferred in DMEM and the adventitias were stripped off with forceps under a binocular microscope. The aortas 
were transferred to a plastic tube containing $5 \mathrm{ml}$ of the enzyme dissociation mixture and incubated for $2 \mathrm{~h}$ at $37^{\circ} \mathrm{C}$ The suspension was centrifuged (1,500 rpm for $10 \mathrm{~min})$ and the pellet was resuspended in DMEM with $10 \%$ FBS Rat aortic VSMCs were cultured in DMEM supplement with $10 \%$ FBS, $100 \mathrm{IU} / \mathrm{ml}$ of penicillin, and $100 \mu \mathrm{g} / \mathrm{ml}$ of streptomycin in $75-\mathrm{cm}^{2}$ flasks at $37^{\circ} \mathrm{C}$ in a humidified atmosphere of $95 \%$ air and $5 \% \mathrm{CO}_{2}$ (Forma Scientific, Inc., Marjetta, $\mathrm{OH})$.

\section{RASMC proliferation assay}

Cellular proliferation was measured by PreMix WST-1 Cell Proliferation Assay System (TAKARA Biomedicals, Shiga, Japan). This system enables measurement of cell proliferation with colorimetric assay based on the cleavage of slightly red tetrazolium salt (WST-1) by mitochondrial succinate-tetrazolium reductase in viable cells. As the increase in enzyme activity leads to an increase of production of formazan dye, the quantity of formazan dye is directly related to the number of metabolically active cells in the medium. Cells $\left(5-7 \times 10^{3}\right)$ were seeded into wells of a 96-well culture plate and incubated with AGEs for the times indicated. WST-1 cell proliferation reagent was added directly to the supernatant $(10 \mu \mathrm{l} / 100 \mu \mathrm{l}$ growth medium) and incubated at $37^{\circ} \mathrm{C}$ for $3 \mathrm{~h}$. The absorbency of the solubilized dark red formazan product was then determined at $450 \mathrm{~nm}$.

\section{AGEs and statin treatment}

Cultured RASMCs were co-incubated with prepared BSA-AGEs solution (Sigma, St. Louis, MO) at each concentration of $1,10,50,100$ and $1,000 \mu \mathrm{g} / \mathrm{ml}$ for $2 \mathrm{~h}$ at $37^{\circ} \mathrm{C}$. Simvastatin (Merck \& Co., Inc., Rahway, NJ) was pretreated for inhibition experiment. AGEs-stimulated RASMCs were incubated with $0.1,1,5,10,20,50$ and $100 \mu \mathrm{M}$ of activated statin for $1 \mathrm{~h}$ before AGEs stimulation. Statin was activated via alkaline hydrolysis as previously described (Jones et al., 2001).

\section{Measurement of intracellular ROS generation}

RASMCs were labeled with 2',7'-dichlorodihydrofluorescein diacetate (H2DCFDA; Molecular Probe, CA) as previously described (Haendeler et al., 2004). The probe H2DCFDA $(5 \mu \mathrm{M})$ entered the cell and the acetate group on H2DCFDA was cleaved by cellular esterases, trapping the non-fluorescent 2',7'-dichlorofluorescin (DCF) inside.

Subsequent oxidation by ROS yields the fluorescent product DCF. The dye, when exposed to an excitation wavelength of $480 \mathrm{~nm}$, emits light at $535 \mathrm{~nm}$ only when it has been oxidized. Labeled RASMCs were examined using a luminescence spectrophotometer for oxidized dye. The quiescent cells were treated with AGEs for $3 \mathrm{~h}$ before labeling with H2DCFDA..

\section{SDS-PAGE and Western blot analysis for NFkB p65, p-ERK, and p-P38}

VSMCs were solubilized in a lysis buffer $(20 \mathrm{mM}$ Tris, $\mathrm{pH}$
7.5, $150 \mathrm{mM} \mathrm{NaCl}, 1 \mathrm{mM} \mathrm{Na} 2$ EDTA, $1 \mathrm{mM}$ EGTA, 1\% Triton, $2.5 \mathrm{mM}$ sodium pyrophosphate, $1 \mathrm{mM} \beta$-glycerophosphate, $1 \mathrm{mM} \mathrm{Na} \mathrm{VO}_{4}, 1 \mathrm{mM} \mathrm{PMSF}, 1 \mu \mathrm{g} / \mathrm{ml}$ aprotinin, and $1 \mu \mathrm{g} / \mathrm{ml}$ leupeptin) and centrifuged at $12,000 \mathrm{~g}$ for 20 $\min$ at $4^{\circ} \mathrm{C}$. The protein concentrations of the supernatants were determined using a Bradford protein assay kit (Bio-Rad, Hercules, CA). Cell lysates containing equal amounts of protein were subjected to SDS-PAGE, and the proteins were transferred to PVDF membrane (Millipore, Bedford, MA). After blocking in $10 \mathrm{mM}$ of Tris- $\mathrm{HCl}$ buffer $(\mathrm{pH}$ 8.0) containing $150 \mathrm{mM}$ of sodium chloride, $0.1 \%$ Tween 20 , and $5 \%(\mathrm{w} / \mathrm{v})$ nonfat dry milk, the membrane was treated with NFkB p65, p-ERK, and p-P38 primary antibodies (Santa Cruz Biotechnology Inc., Santa Cruz, $\mathrm{CA}$ ), followed by incubation with appropriate HRP-conjugated secondary antibodies. The antigen-antibody bands were detected using an enhanced chemiluminescence reagent kit (Amersham Bioscience, Uppsala, Sweden) and quantified by densitometry.

\section{RNA interference for RAGE mRNA}

For function-blocking experiments, siRNA molecules targeted at receptor for AGE (RAGE) mRNA was used. A 21-nt sequence for siRNA was derived from rat RAGE (GenBank accession No. GI: 81722) and obtained from Ambion, Inc. (TX): siRNA against RAGE (sense, 5'-GCUAGAAUGGAAACUGAACtt-3'; antisense, 5'-GUUCAGUUUCCAUUCUAGCtt-3'). RSMCs were transfected with si-RAGE duplexes by using siPORT NeoFX (Ambion).

Briefly, RNA duplex (10 $\mathrm{nM}$ of final concentration) was incubated in serum-free DMEM containing $15 \mu \mathrm{l}$ of siPORT NeoFX for $10 \mathrm{~min}$. The complex was added to the empty $60 \mathrm{~mm}$ culture plate and then overlay SMC suspension (1 $\times 10^{5}$ cells per plate) onto the culture plate wells containing transfection complexes. The transfected cells were incubated in normal cell culture conditions until ready for assay.

\section{RT-PCR analysis for COX-2 and c-jun}

Total RNA was prepared by the Ultraspect ${ }^{\mathrm{TM}}{ }^{-}$-II RNA system (Biotecx Laboratories, Inc., TX), and single-stranded cDNA was then synthesized from isolated total RNA by avian myeloblastosis virus (AMV) reverse transcriptase. A $20 \mu \mathrm{l}$ reverse transcription reaction mixture containing $1 \mu \mathrm{g}$ of total RNA, $1 \times$ reverse transcription buffer $(10 \mathrm{mM}$ Tris- $\mathrm{HCl}$, $\mathrm{pH} 9.0,50 \mathrm{mM} \mathrm{KCl}, 0.1 \%$ Triton X-100), $1 \mathrm{mM}$ deoxynucleoside triphosphates (dNTPs) 0.5 unit of RNase inhibitor, $0.5 \mu \mathrm{g}$ of oligo (dT)15, and 15 units of AMV reverse transcriptase was incubated at $42^{\circ} \mathrm{C}$ for $15 \mathrm{~min}$, heated to $99^{\circ} \mathrm{C}$ for $5 \mathrm{~min}$, and then incubated at $0-5^{\circ} \mathrm{C}$ for $5 \mathrm{~min}$. PCRs were performed for 35 cycles with $3^{\prime}$ and $5^{\prime}$ primers based on the sequences of various genes. Primers were as follows: c-jun: 5'-AACGACCTTCTACGACGATG-3', 5'GCAGCGTATTCTGGCTATGC-3' (364bp); COX-2: 5'-TCCAATCGCTGTACAAGCAG-3', 5'-TCCCCAAAGATAGCATCTGC-3' (230 bp). GAPDH (primers 5'-ACCACAGTCCATGCCATCAC-3' and 5'-TCCACCACCCTGTTGCTGTA-3' (450 bp) was used as the internal standard. The signal intensity of the amplification product was normalized to its respective GAPDH signal intensity. 


\section{Induction of neointimal formation after balloon denudation in diabetic rat carotid artery}

Balloon denudation of the common carotid artery endothelium was evoked in 16-wk-old diabetic Sprague-Dawley rats $(400 \mathrm{~g}$ ). Under isoflurane (Abbott Laboratories, St. Laurent, QC) anesthesia, a neck midline incision was made and after exposure of the left carotid artery, a $2 \mathrm{~F}$ Fogarty balloon catheter (Edwards Lifesciences, Mississauga, ON) was inserted into the external carotid branch to the aortic arch and insufflated (with about $0.2 \mathrm{ml}$ of saline) to produce slight resistance and withdrawn 3 times. After $4 \mathrm{wk}$, they were compared to sham-operated controls in which the same procedure was performed, except balloon insertion. Animal housing and experimentation in accordance with Animal Care and NIH guidelines were approved by the local animal care committee.

\section{Perfusion of vessels, hematoxylin and eosin staining, and immunochemistry for COX-2 in rat carotid artery}

The hearts were perfused with Krebs-Ringer Bicarbonate Buffer (KRBB: $120 \mathrm{mM} \mathrm{NaCl}, 25 \mathrm{mM} \mathrm{NaHCO}_{3}, 5 \mathrm{mM} \mathrm{KCl}$, $1.2 \mathrm{mM} \mathrm{KH}_{2} \mathrm{PO}_{4}, 1.2 \mathrm{mM} \mathrm{MgSO}_{4}, 2.5 \mathrm{mM} \mathrm{CaCl}_{2}$, and 20 $\mathrm{mM}$ MOPS) for $10 \mathrm{~min}$ to wash out the blood, and then fixed with $10 \%$ formalin.

The carotid arteries were sliced transversely. Within $24 \mathrm{~h}$ after fixation, each of the sections was embedded in paraffin. Serial $2 \mu \mathrm{m}$ artery sections were cut with microtome and mounted on siliconized slides. Paraffin sections were stained with hematoxylin and eosin (H\&E) and evaluated with light microscopy to assess the histological effects. Normal and neointimal areas were measured using NIH images.

Serial sections were prepared and immunohistochemistry to detect COX-2 was performed using polyclonal monospecific antibodies to COX-2 (Abcam plc., Cambridge, UK).

\section{Statistical analysis}

Data are presented as mean \pm SEM. Differences between 2 experimental groups were examined by Student's $t$ test. One-way ANOVA followed by post hoc paired comparisons for comparison of multiple groups and ANOVA for repeated measures were used as appropriate (SPSS software). A value of $P<0.05$ was considered significant.

\section{Acknowledgments}

We gratefully acknowledge the assistance of the researchers at the Cardiovascular Research Institute, Yonsei Cardiovascular Hospital, Yonsei University College of Medicine, in the preparation and interpretation of the data. This study was supported by the Brain Korea 21 Project for Medical Science, Yonsei University and the Korean Institute of Medicine and a research grant from MSD (Merck \& Co., Inc., New Jersey, Ltd.).

\section{References}

Arumugam T, Simeone DM, Golen KV, Logsdon CD. S100P
Promotes Pancreatic Cancer Growth, Survival, and Invasion. Clin Cancer Res 2005;11:5356-64

Arumugam T, Simeone DM, Schmidt AM, Logsdon CD. S100P stimulates cell proliferation and survival via receptor for advanced glycation end products RAGE. J Biol Chem 2004;279:5059-65

Baynes JW, Thorpe SR. Role of oxidative stress in diabetic complications: a new perspective on an old paradigm. Diabetes 1999;48:1-9

Bierhaus A, Chevion S, Chevion M, Hofmann M, Quehenberger P, Illmer T, Luther T, Berentshtein E, Tritschler H, Müller M, Wahl P, Ziegler R, Nawroth PP. Advanced glycation endproduct-induced activation of $N F K B$ is suppressed by alpha-lipooic acid in cultured endothelial cells. Diabetes 1997;46:1481-90

Brown MR, Miller FJ Jr, Li WG, Ellingson AN, Mozena JD, Chatterjee P, Engelhardt JF, Zwacka RM, Oberley LW, Fang $X$, Spector AA, Weintraub NL. Overexpression of human catalase inhibits proliferation and promotes apoptosis in vascular smooth muscle cells. Circ Res 1999;85:524-33

Brownlee M, Cerami A, Vlassara H. Advanced glycation end product in tissue and the biochemical basis of diabetic complications. N Engl J Med 1988;318:1315-23

Burleigh ME, Babaev VR, Oates JA, Harris RC, Gautam S, Riendeau D, Marnett LJ, Morrow JD, Fazio S, Linton MF. Cyclooxygenase-2 promotes early atherosclerotic lesion formation in LDL receptor-deficient mice. Circulation 2002;105:1816-23

Chen Z, Fukutomi T, Zago AC, Ehlers R, Detmers PA, Wright SD, Rogers C, Simon DI. Simvastatin Reduces Neointimal Thickening in Low-Density Lipoprotein Receptor-Deficient Mice After Experimental Angioplasty Without Changing Plasma Lipids. Circulation 2002;106:20-3

Cipollone F, lezzi A, Fazia M, Zucchelli M, Pini B, Cuccurullo C, De Cesare D, De Blasis G, Muraro R, Bei R, Chiarelli F, Schmidt AM, Cuccurullo F, Mezzetti A. The receptor RAGE as a progression factor amplifying arachidonate-dependent inflammatory and proteolytic response in human atherosclerotic plaques: role of glycemic control. Circulation 2003; 108:1070-7

Cuccurullo C, lezzi A, Fazia ML, De Cesare D, Di Francesco A, Muraro R, Bei R, Ucchino S, Spigonardo F, Chiarelli F, Schmidt AM, Cuccurullo F, Mezzetti A, Cipollone F. Suppression of Rage as a Basis of Simvastatin-Dependent Plaque Stabilization in Type 2 Diabetes. Arterioscler Thromb Vasc Biol 2006;26:2716-23

Davignon J. Beneficial Cardiovascular Pleiotropic Effects of Statins. Circulation 2004;109(suppl III):III-39-III-43

Giroux LM, Davignon J, Naruszewicz M. Simvastatin inhibits the oxidation of low-density lipoproteins by activated human monocyte-derived macrophages. Biochim Biophys Acta 1993;1165:335-8

Haendeler J, Hoffmann J, Zeiher AM, Dimmeler S. Antioxidant effects of statins via S-nitrosylation and activation of thioredoxin in endothelial cells. Circulation 2004;110:851-61 Hong BK, Kwon HM, Lee BK, Kim D, Kim IJ, Kang SM, Jang 
Y, Cho SH, Kim HK, Jang BC, Cho SY, Kim HS, Kim MS, Kwon HC, Lee N. Coexpression of cyclooxygenase-2 and matrix metalloproteinases in human aortic atherosclerotic lesions. Yonsei Med J 2000;41:82-8

Jones SP, Trocha SD, Lefer DJ. Pretreatment with simvastatin attenuates myocardial dysfunction after ischemia and chronic reperfusion. Circulation 2001;21:2059-64

Kanauchi M, Hashimoto T, Tsujimoto N. Advanced Glycation End Products in Nondiabetic Patients With Coronary Artery Disease. Diabetes Care 2001;24:1620-3

Kim SE, Thanh Thuy TT, Lee JH, Ro JY, Bae YA, Kong Y, Ahn JY, Lee DS, Oh YM, Lee SD, Lee YS. Simvastatin inhibits induction of matrix metalloproteinase- 9 in rat alveolar macrophages exposed to cigarette smoke extract. Exp Mol Med 2009;41:277-87

Komukai M, Wajima YS, Tashiro J, Shinomiya M, Saito Y, Morisaki N. Carvastatin suppresses intimal thickening of rabbit carotid artery after balloon catheter injury probably through the inhibition of vascular smooth muscle cell proliferation and migration. Scand J Clin Lab Invest 1999; 59:159-66

Kornowski R, Mintz GS, Kent KM, Pichard AD, Satler LF, Bucher TA, Hong MK, Popma JJ, Leon MB. Increased restenosis in diabetes mellitus after coronary interventions is due to exaggerated intimal hyperplasia. A serial intravascular ultrasound study. Circulation 1997;95:1366-9

Oda $\mathrm{H}$, Keane WF. Recent advances in statins and the kidney. Kidney Int 1999;71(Suppl):S2-S5

Park SH, Marso SP, Zhou Z, Foroudi F, Topol EJ, Lincoff AM. Neointimal hyperplasia after arterial injury is increased in a rat model of non-insulin-dependent diabetes mellitus. Circulation 2001;104:815-9

Pontsler AV, St Hilaire A, Marathe GK, Zimmerman GA, Mclntyre TM. Cyclooxygenase-2 is induced in monocytes by peroxisome proliferator activated receptor gamma and oxidized alkyl phospholipids from oxidized low density lipoprotein. J Biol Chem 2002;277:13029-36

Rauvala H, Huttunen HJ, Fages C, Kaksonen M, Kinnunen T, Imai S, Raulo E, Kilpeläinen I. Heparin-binding proteins HB-GAM (pleiotrophin) and amphoterin in the regulation of cell motility. Matrix Biol 2000;19:377-87

Rojas A, Morales MA. Advanced glycation and endothelial functions: A link towards vascular complications in diabetes. Life Sciences 2004;76:715-30
Sakaguchi T, Yan SF, Yan SD, Belov D, Rong LL, Sousa M, Andrassy M, Marso SP, Duda S, Arnold B, Liliensiek B, Nawroth PP, Stern DM, Schmidt AM, Naka Y. Central role of RAGE-dependent neointimal expansion in arterial restenosis. J Clin Invest 2003;111:959-72

Schonbeck U, Sukhova G, Graber P, Coulter S, Libby P. Augmented expression of cyclooxygenase-2 in human atherosclerotic lesions. Am J Pathol 1999;155:1281-91

Senokuchi T, Matsumura T, Sakai M, Yano M, Taguchi T, Matsuo T, Sonoda K, Kukidome D, Imoto K, Nishikawa T, Kim-Mitsuyama S, Takuwa Y, Araki E. Statins suppress oxidized low density lipoprotein-induced macrophage proliferation by inactivation of the small $\mathrm{G}$ protein-p38 MAPK pathway. J biol. chem. 2005;280:6627-33

Shanmugam N, Kim YS, Lanting L, Natarajan R. Regulation of Cyclooxygenase-2 Expression in Monocytes by Ligation of the Receptor for Advanced Glycation End Products. J Biol Chem 2003;278:34834-44

Singh R, Singh N, Rastogi S. Antioxidants effects of lovastatin and vitamin $\mathrm{E}$ on experimental atherosclerosis in rabbits. Cardiovasc Drugs Ther 1997;11:575-80

Stephenson K, Tunstead J, Tsai A, Gordon R, Henderson S, Dansky HM. Neointimal formation after endovascular arterial injury is markedly attenuated in $\mathrm{db} / \mathrm{db}$ mice. Arterioscler Thromb Vasc Biol 2003;23:2027-33

Taguchi A, Blood DC, del Toro G, Canet A, Lee DC, Qu W, Tanji N, Lu Y, Lalla E, Fu C, Hofmann MA, Kislinger T, Ingram M, Lu A, Tanaka H, Hori O, Ogawa S, Stern DM, Schmidt AM. Blockade of RAGE-amphoterin signalling suppresses tumour growth and metastases. Nature 2000;405:354-60

Takemoto M, Liao JK. Pleiotropic effects of 3-hydroxy-3methylglutaryl coenzyme A reductase inhibitors. Arterioscler Thromb Vasc Biol 2001;21:1712-9

Takemoto M, Node K, Hironori N. Statins as antioxidant therapy for preventing cardiac myocyte hypertrophy. J Clin Invest 2001;108:1429-37

Wassmann S, Laufs U, Müller K, Konkol C, Ahlbory K, Bäumer AT, Linz W, Böhm M, Nickenig G. Cellular antioxidant effects of atorvastatin in vitro and in vivo. Arterioscler Thromb Vasc Biol 2002;22:300-5

Zhou Z, Wang K, Penn MS, Marso SP, Lauer MA, Forudi F, Zhou X, Qu W, Lu Y, Stern DM, Schmidt AM, Lincoff AM, Topol EJ. Receptor for AGEs (RAGE) mediates neointimal formation in response to arterial injury. Circulation 2003;107:2238-43 